\title{
Gamma Knife radiosurgery for cerebral arteriovenous malformations: a systematic review and meta-analysis
}

\author{
Musa China ${ }^{1,2}\left(\right.$ Amisha Vastani $^{2} \cdot$ Ciaran Scott Hill $^{2,3} \cdot$ Cornel Tancu $^{2} \cdot$ Patrick J. Grover $^{2}$
}

Received: 23 December 2021 / Revised: 28 January 2022 / Accepted: 1 February 2022 / Published online: 18 February 2022

(c) Crown 2022

Keywords Arteriovenous malformation $\cdot$ AVM $\cdot$ Gamma knife radiosurgery $\cdot$ Stereotactic radiosurgery $\cdot$ Intracranial haemorrhage $\cdot$ Radiation-induced changes

\section{Introduction}

Cerebral arteriovenous malformations (AVMs) are rare vascular lesions that rupture at an approximate annual rate of $2-4 \%$ [1]. Annual haemorrhage rates range from $<1 \%$, for unruptured superficially located AVMs, up to $33 \%$ in ruptured AVMs with deep, location and venous drainage $[12,68]$. Once haemorrhage occurs, the probability of experiencing new neurological deficit has been reported to be up to $50 \%$ and fatality $~ 10 \%[28,66]$. Gamma knife radiosurgery (GKRS) is an established intervention predominantly favoured for small $(<3.5 \mathrm{~cm})$, surgically high-risk or complex AVMs. Successful AVM GKRS is contingent on abolishing the risk of intracranial haemorrhage (ICH) via complete nidal obliteration, whilst limiting the development of new neurological deficit from radiation-induced changes (RICs) [9, 26, 69].

The complications of AVM GKRS are mainly two-fold. Firstly, patients remain at risk of haemorrhage during the latency period between GKRS and nidus obliteration. The relative risk of AVM haemorrhage during this latency period versus the natural history of an untreated AVM remains a

Musa China and Amisha Vastani are joint first authors.

Musa China and Amisha Vastani contributed equally to this work.

Musa China

musa.china.15@ucl.ac.uk

1 Division of Medicine, University College London (UCL), London, UK

2 Department of Neurosurgery, National Hospital for Neurology and Neurosurgery, Queen Square, London, UK

3 Cancer Biology Division, The UCL Cancer Institute, University College London, London WC1E 6DD, UK topic of debate [26, 28]. Secondly, RICs can occur following radiosurgery, influenced by AVM and treatment parameters including AVM volume, location and treatment dose [12]. Approximately 34\% of patients develop RICs, 8\% of patients develop RIC-related neurological symptoms and $\sim 3 \%$ will experience permanent neurologic deterioration. However, considerable variations in the reported rates, durations and definition of RICs still remain. Further, delayed adverse effects including radiation necrosis and cyst formation following GKRS have been reported, yet there is a paucity of literature conclusively describing their incidence [38].

A previous systematic review and meta-analysis quantified haemorrhage risk and obliteration rate following AVM stereotactic radiosurgery (SRS), but it had limitations [72]. The review included 69 observational studies, of which, however, approximately only a third solely treated AVMs with GKRS; the majority reporting on linear accelerator (LINAC) or other SRSmodalities. Additionally, the median duration of study followup was less than three years; an arguably limited time-frame to comprehensively analyse clinical outcomes of AVM GKRS, which evolve in a time-dependent manner over a latency period of 2-3 years following radiosurgical intervention $[1,12,68]$.

Alongside imaging advancements and increasingly sophisticated radiation delivery systems since the inception of GKRS, there has also been an increasing knowledge base on AVM obliteration, RICs and post-GKRS ICH [12]. Whilst there are several studies that review or report on these outcomes, none are both systematic or comprehensive. We sought to systematically review the current literature and comprehensively quantify the efficacy: complication profile of GKRS for cerebral AVMs. 


\section{Materials and methods}

\section{Registration and reporting standards}

We performed this systematic review following the Preferred Reporting Items for Systematic Reviews and Meta-Analyses (PRISMA) guidelines (Appendix 1) [53]. The study protocol is published on PROSPERO (CRD 42,021,285,118).

\section{Search strategy}

We performed a comprehensive literature search (Appendix 2) using OVID Medline, EMBASE, ClinicalTrials.gov, OpenGrey and Cochrane Library from 1st January 1989 to 1st September 2021 for relevant articles. We reviewed the bibliographies of included studies for further articles meeting our eligibility criteria.

\section{Eligibility criteria}

We sought randomised trials and observational cohort studies, published in English in peer-reviewed journals reporting $20+$ adult $(18+)$ patients with AVMs, diagnosed by MRI or histopathological examination, treated with single-session GKRS. We included studies describing all the following patient and AVM characteristics: (1) median (or mean) margin dose, (2) AVM volume (or maximum nidus diameter), (3) clinical presentation, (4) AVM Spetzler-Martin grades. We included studies reporting all the following clinical and radiological outcomes, with a minimum follow-up period of 12 months following GKRS: (1) complete nidus obliteration rate (angiography or angiography/MRI-confirmed), (2) postGKRS ICH, (3) RICs or adverse radiation effects (ARE).

\section{Study selection}

Two investigators (MC and AV) independently screened all titles and abstracts for eligibility. The full text of eligible studies was reviewed for inclusion. CSH, CT and PG acted as mediators in cases of disagreement. If multiple studies with overlapping data from a single institution were published, the study reporting the largest sample size and/or the most recent study were prioritised (Appendix 3 and 4).

\section{Data extraction}

Data extraction was performed independently by two authors (MC and AV) from each unique study cohort undergoing GKRS to ensure consistent extraction of patient, AVM and treatment characteristics. We extracted the following outcomes: complete nidus obliteration rate, $\mathrm{ICH}$, radiologic evidence of RIC, symptomatic RIC events (transient or permanent), radionecrosis, cyst formation, radiation-induced neoplasm, seizures (new or worsening), deaths attributed to AVM/GKRS (case-related) and all-cause death rate.

We used outcomes as described per patient. The proportion successfully obliterated was calculated as a proportion of all patients with available radiological follow-up and was defined as the presence of angiographically demonstrated complete obliteration and/or angiography-or-MRI confirmed obliteration. Post-GKRS ICH was defined as any AVMrelated haemorrhage detected through appropriate followup radiological imaging. RICs were classified as follows: (1) total radiologic RIC: any MRI evidence of peri-nidal T2-weighted hyperintensities after GKRS; (2) transient symptomatic RIC: radiologic RIC which correlated with new or worsening neurological symptoms, typically headache, seizure or focal neurological deficit, which resolved by the end of study follow-up; and (3) permanent RIC: symptomatic RIC without full recovery to pre-GKRS neurological baseline at the end of study follow-up.

\section{Risk of bias}

Two authors (MC and AV) assessed the risk of bias of each cohort as serious, moderate, low, or unclear risk according to the following domains of the Cochrane ROBINS-I tool [70]: (1) confounding bias, (2) selection bias, (3) bias in classification of interventions, (4) bias due to deviations from intended interventions, (5) attrition bias, (6) detection bias and (7) selective outcome reporting (Appendix 5).

\section{Statistical analysis}

We quantified the distribution of cohort-level characteristics with descriptive analyses. We calculated the incidence of clinical outcomes as a proportion of total patients treated with GKRS. We quantified the occurrence of haemorrhage and fatality at any time after GKRS either during the total person-years of follow-up stated or by multiplying the median (or mean) follow-up duration by total number of patients treated. We calculated annual incidence rates for haemorrhage and fatality, using Poisson distributions.

We aimed to perform the following subgroup analyses: (1) clinical and obliteration outcomes reported in studies stratifying by AVM Spetzler-Martin grades [67]: I-II, III and IV-V; (2) clinical and obliteration outcomes reported in studies stratifying by Radiosurgery-Based AVM Score [61, 62].

A meta-analysis was performed for all primary outcomes. DerSimonian-Laird random effects models were used for all summary effect estimates with a Freeman-Tukey double arcsine transformation $[11,25]$. 
Heterogeneity was assessed using the quantity $I^{2}$ [34]. Heterogeneity was investigated using Baujat plots [3] and leaveone-out sensitivity analysis. Publication bias was assessed using Funnel plots and Egger's test was performed to assess Funnel plot symmetry.

Moderator analysis was performed using meta-regression techniques to determine association of patient, AVM and treatment characteristics with clinical and radiological outcomes. Patients were stratified by the following prespecified variables: age, sex, study mid-year, median margin treatment dose (Gy), median AVM volume $\left(\mathrm{cm}^{3}\right)$, deep location (\%), eloquent location (\%), deep venous drainage (\%).

$\mathrm{R}$ version 4.0.4 (The R Foundation for Statistical Computing, Vienna, Austria) was used for all statistical analyses. For all statistical tests, $P<0.05$ was considered statistically significant.

\section{Results}

\section{Study selection}

After screening 3402 publications, 166 full-text studies were reviewed with 34 studies included in final analysis (Fig. 1, Appendix 3,4). A detailed summary of included studies is presented in Appendix 6.

\section{Study characteristics}

In the 35 cohorts (34 studies) receiving GKRS, including a total of 8673 patients with 41,544 patient-years of follow-up, the median cohort-level patient characteristics were: population size 182 patients, age at initial treatment 35 years, 53\% male, follow-up duration 60 months, $49 \%$ presented with ICH, 71\% AVMs were lobar, 20\% deep and $72 \%$ in eloquent locations (Table 1 and Appendix 6).
Fig. 1 PRISMA flowchart of search strategy used for the systematic review. Arteriovenous malformation (AVM), gammaknife radiosurgery (GKRS), linear accelerator (LINAC), Spetzler-Martin (SM)

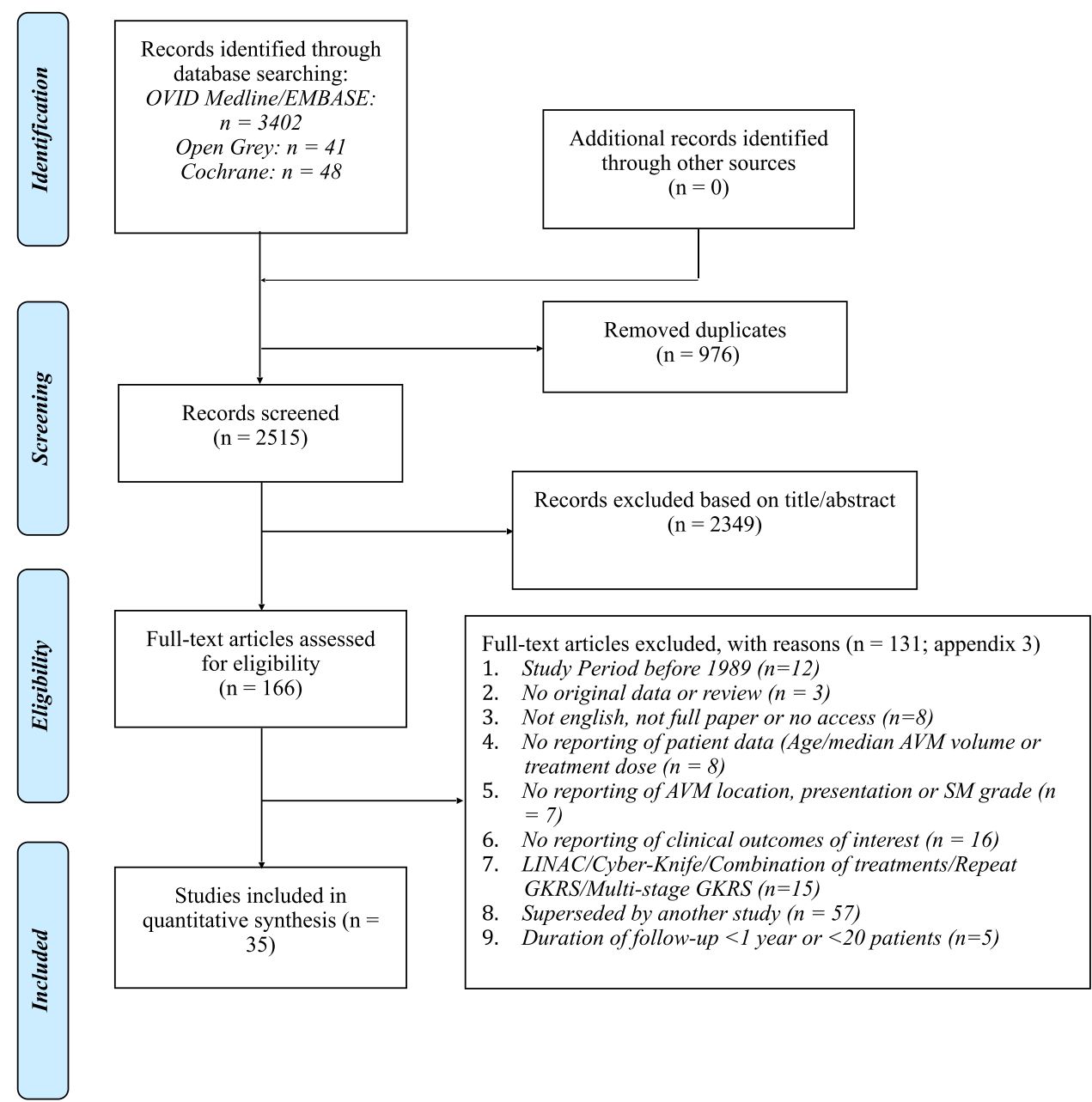


Table 1 Summary characteristics of all studies: single-stage gamma knife radiosurgery (GKRS) intervention for brain arteriovenous malformations (AVMs)

\begin{tabular}{|c|c|c|c|}
\hline Characteristics & Median (Interquartile range) & Cohorts reporting characteristics & Patients reported \\
\hline \multicolumn{4}{|l|}{ Demographics } \\
\hline Number of patients & $182(98-278)$ & 35 & 8673 \\
\hline Age, years & $35.1(30.9-40.0)$ & 35 & 8673 \\
\hline Male:Female, $\%$ & $53: 47$ & 35 & 8673 \\
\hline Duration of Follow-up, mo & $60.2(37.0-78.8)$ & $33^{\mathrm{a}}$ & 8355 \\
\hline Follow-up person-years, y & $547.3(244.1-1555)$ & $33^{\mathrm{a}}$ & 8355 \\
\hline Mid-year study period & $2001(1998-2005)$ & 35 & 8673 \\
\hline \multicolumn{4}{|l|}{ Presentation, $\%$} \\
\hline Ruptured AVM & $49.3(36-58.8)$ & 35 & 8673 \\
\hline Clinical presentation: seizures ${ }^{\mathrm{b}}$ & $23(18.8-31.5)$ & 27 & 4931 \\
\hline Clinical presentation: incidental finding & $8(3-14)$ & 19 & 3697 \\
\hline \multicolumn{4}{|l|}{ Previous intervention, $\%$} \\
\hline Embolisation & $13.4(2.3-22.6)$ & 33 & 8436 \\
\hline Surgical resection & $6.7(2.5-9.7)$ & 28 & 7842 \\
\hline Previous Radiosurgery (including GKRS/LINAC/CK) & $0(0-1.2)$ & 34 & 8436 \\
\hline \multicolumn{4}{|l|}{ Angioarchitecture } \\
\hline Nidus Volume ${ }^{\mathrm{c}}, \mathrm{cm}^{3}$ & $3.9(2.6-4.9)$ & 33 & 8595 \\
\hline Nidus Diameter Max., cm & $2.3(2.0-2.8)$ & 20 & 6430 \\
\hline \multicolumn{4}{|l|}{ Venous Drainage $^{\mathrm{a}}$} \\
\hline Superficial only & $44(34.6-67.2)$ & 12 & 4835 \\
\hline Deep & $56(32.9-65.4)$ & 13 & 5170 \\
\hline Associated Aneurysm ${ }^{\mathrm{f}}, \%$ & $10.4(6.7-14.6)$ & 15 & 4320 \\
\hline \multicolumn{4}{|l|}{ Location, $\%$} \\
\hline Eloquent, \% & $71.6(59.8-91.5)$ & 16 & 5407 \\
\hline Deep $^{\mathrm{a}}, \%$ & $19.5(12.7-35.7)$ & 31 & 8116 \\
\hline Basal Ganglia/Thalamus & $8.5(4-15.2)$ & 19 & 3312 \\
\hline Brainstem & $3.5(0.7-11.8)$ & 19 & 3312 \\
\hline Lobar $^{g}, \%$ & $71.3(52.7-82.9)$ & 27 & 7730 \\
\hline Cerebellum, \% & $7.3(0-8.8)$ & 21 & 3919 \\
\hline \multicolumn{4}{|l|}{ Spetzler-Martin grade } \\
\hline SM1, \% & $11.8(4.5-17.2)$ & $30^{d}$ & 7586 \\
\hline $\mathrm{SM} 2, \%$ & $32.9(21-39.3)$ & $30^{d}$ & 7586 \\
\hline SM3, $\%$ & $36.6(29.4-45.8)$ & $32^{e}$ & 7640 \\
\hline $\mathrm{SM} 4, \%$ & $9.8(1.7-14.7)$ & $29^{e}$ & 6994 \\
\hline SM5, $\%$ & $0(0-1.9)$ & $29^{e}$ & 6994 \\
\hline SM6, $\%$ & $0(0-0)$ & $29^{e}$ & 6994 \\
\hline RBAS & $1.4(1.2-1.5)$ & 16 & 4780 \\
\hline \multicolumn{4}{|l|}{ Treatment characteristics } \\
\hline Marginal GK dose, Gy & $20(19-22)$ & 35 & 8673 \\
\hline Maximum GK dose, Gy & $37.9(36-40)$ & 19 & 3679 \\
\hline Repeat GK performed, $\%$ & $13.2(6.8-18.7)$ & 26 & 5461 \\
\hline
\end{tabular}

Arteriovenous malformation (AVM), cyber-knife (CK), gamma-knife/radiosurgery (GK/RS), linear accelerator (LINAC), radiosurgery-based AVM Score (RBAS), Spetzler-Martin (SM)

${ }^{a}$ Follow-up missing: Franzin et al. 2013 [24] and Nicolato et al. 2002 [54] did not include median FU duration, except including minimum FU duration (see Appendix 6). Pollock et al. 2016 [64] grouped both cohorts 1990-1999 and 1999-2009 together for a total 2966 patient years

${ }^{b}$ Seizure presentation missing: Orio et al. 2006 [56], Hirschmann et al. 2019 [35], Hasegawa et al. 2018 [32], Bir et al. 2015 [4], Chen et al. 2018 [7], Kano et al. 2012 [41], Pollock et al. 2016 [64] (1990-1999 cohort), Pollock et al. 2016 [64] (1999-2009 cohort)

${ }^{\mathrm{c}}$ Volume missing: Ditty et al. 2017[18]

${ }^{\mathrm{d}}$ SM-grade not included and not possible to calculate according to data provided within these select papers. Pollock et al. 2016 [64] 19901999/1999-2009 cohorts and Hirschmann et al. 2019 [35] reported Spetzler-Ponce classification which did not stratify SM 1/2 or SM 4/5 grade AVMs further. Orio et al. 2006 [56] and Zhao et al.2008 [75] did not report venous drainage

${ }^{\mathrm{e}}$ In addition to the previously stated papers, Hasegawa et al. 2018 [32] does not stratify individually but groups SM 3-5 AVMs frequency (55\%)

${ }^{\mathrm{f}}$ Includes both flow-related and intra-nidal aneurysm

${ }^{g}$ Includes all AVMs labelled as Hemispheric/lobar/superficial without any further analysis 
Table 2 Outcomes/incidence rate following single-stage gamma knife radiosurgery for brain arteriovenous malformations

\begin{tabular}{|c|c|c|c|c|c|c|}
\hline Outcomes & Cohorts, $n(/ 35)$ & Patients & $\begin{array}{l}\text { Number of outcome } \\
\text { events/total no. of } \\
\text { patients }(\%)\end{array}$ & $\begin{array}{l}\text { Median rate, } \% \\
\text { (range) }\end{array}$ & $\begin{array}{l}\text { Number of outcome } \\
\text { events/total person- } \\
\text { years }^{\mathrm{a}}\end{array}$ & $\begin{array}{l}\text { Estimate annual inci- } \\
\text { dence, } \%(95 \% \mathrm{CI}) \text { per } \\
100 \text { person-years }\end{array}$ \\
\hline Haemorrhage & $35^{\mathrm{a}}$ & 8673 & $576 / 8673(6.64 \%)$ & $\begin{array}{l}6.2 \%(2.01-18.18) \\
\text { Median months post- } \\
\text { GKRS: } 19.7\end{array}$ & $576 / 41554$ & $1.38(1.28-1.50)$ \\
\hline Total RIC & 18 & 4369 & $1268 / 4369(29.0 \%)$ & $29.8 \%(0-63.3)$ & & \\
\hline $\begin{array}{l}\text { Transient sympto- } \\
\text { matic RIC }\end{array}$ & $22^{\mathrm{f}}$ & 5685 & $339 / 5685(5.96 \%)$ & $6.29 \%(0-17.07)$ & & \\
\hline $\begin{array}{l}\text { Permanent sympto- } \\
\text { matic RIC }\end{array}$ & $28^{\mathrm{g}}$ & 6961 & $175 / 6961(2.51 \%)$ & $2.67 \%(0-10.45)$ & & \\
\hline $\begin{array}{l}\text { Mortality }\left(2^{\circ} \text { to } \mathrm{ICH} /\right. \\
\text { RIC) }\end{array}$ & $23^{c}$ & 4240 & $88 / 4240(2.08 \%)$ & $1.89 \%(0.38-7.46)$ & $88 / 19075$ & $0.46(0.37-0.57)$ \\
\hline Mortality (all-cause) & 24 & 6401 & $212 / 6401(3.31 \%)$ & $2.36 \%(0.42-14.93)$ & $212 / 31483$ & $0.67(0.58-0.76)$ \\
\hline $\begin{array}{l}\text { Seizure (new-onset } \\
\text { or increased fre- } \\
\text { quency) }\end{array}$ & 17 & 3385 & $104 / 3385(3.07 \%)$ & $1.76 \%(0-11.8)$ & & \\
\hline Radionecrosis & 8 & 1010 & $22 / 1010(2.18 \%)$ & $2.5 \%(0-6.9)$ & & \\
\hline $\begin{array}{l}\text { Cyst Formation/ } \\
\text { encapsulated } \\
\text { haematoma }^{\mathrm{e}}\end{array}$ & 15 & 3446 & $70 / 3446(2.03 \%)$ & $1.18 \%(0-5.91)$ & & \\
\hline $\begin{array}{l}\text { Radiation-induced } \\
\text { neoplasm }\end{array}$ & 4 & 946 & $1 / 946(0.11 \%)$ & $0 \%(0-0.34 \%)$ & & \\
\hline
\end{tabular}

Gamma-knife radiosurgery (GKRS), intracranial haemorrhage (ICH), radiation-induced changes (RIC)

${ }^{a}$ Total person years at risk of haemorrhage: sum of person-years of follow-up described or by multiplying the median (or mean if median not provided) follow-up duration by total number of treated patients. Franzin et al. 2013 [24] and Nicolato et al. 2002 [54] follow-up stated as 'minimum 36 months' and ' 6 months minimum'. Total haemorrhage risk patient-years follow up for all 32 cohorts was calculated with the median follow up person-years average of 32 cohorts (529.15) assumed for Franzin et al. 2013 and Nicolato et al.2002. Pollock et al. 2016 [64] grouped both cohorts 1990-1999/1999-2009 together for haemorrhage and RICs which has been accounted for

${ }^{b}$ Hirschmann et al. 2019 [35], grouped 'radiologically diagnosed oedema or late onset cyst formation with or without new neurological symptoms' under one total RICs group, with no separation into transient or permanent. Hu et al. 2020 [36], grouped all RICs in one total RIC group, with no separation of transient or permanent. Pollock et al. 2016 [64] grouped both cohorts 1990-1999 and 1999-2009 together for Haemorrhage and RICs which has been accounted for in the table

${ }^{\mathrm{c}}$ Chen et al. 2018 [7] does not specify cause of deaths

${ }^{\mathrm{d}}$ Missing Transient RIC data: Parkhutik et al. 2013 [56], Pollock et al. 2016 [64] 1990-1999, 1999-2009 cohort, Franzin et al. 2013 [24], Orio et al. 2006[56]

${ }^{\mathrm{e}}$ Cyst Formation includes either asymptomatic (radiological-only) or symptomatic presentation

${ }^{\mathrm{f}}$ Ding et al. [14-16], Kano et al. [45] classified headache as TRIC event. Ding et al. [14-16] and Kano et al. [45] classified seizure as TRIC

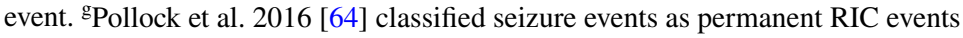

Thirty-three (97\%) studies were from single centres and one (3\%) was multi-centre (Appendix 7). Thirteen (39\%) studies were from North America [4, 14-16, 18, 41, 43-45, 52, 56, 66, 74], 12 (36\%) from Asia [5, 6, 8, 31, 32, 36, 39,
$46,47,51,57,75]$ and $8(24 \%)$ from Europe $[2,24,35,49$, $54,58,65,71]$.

Overall, included studies were at moderate risk of bias (Appendix 5). All studies were at moderate risk of bias due

Table 3 Obliteration rates following single-session GKRS for brain AVMs

\begin{tabular}{lllll}
\hline Obliteration rate & Angiography confirmed & Cohorts, $n$ & Angiography or MRI-confirmed & Cohorts, $n$ \\
\hline Obliteration Rate $(n /$ total patients) & $56.7 \%(3092 / 5450)$ & 21 & $67.80 \%(4605 / 6792)$ & 29 \\
Meta-analysis pooled estimate & $60.5 \%(54.2-66.7)$ & 21 & $69.68 \%(65.89-73.48)$ & 29 \\
Median obliteration rate & $58.3 \%(33.6-87.8)$ & 21 & $69.80 \%(42.42-87.80)$ & 29 \\
$\begin{array}{l}\text { Median obliteration rate (cohorts with } \\
\quad \text { minimum 2 years follow-up) }\end{array}$ & $63.5 \%(33.6-87.8)$ & 14 & $70.85 \%(42.42-87.79)$ & 19 \\
\hline
\end{tabular}

Arteriovenous malformation (AVM), gamma-knife radiosurgery (GKRS), magnetic resonance imaging (MRI) 


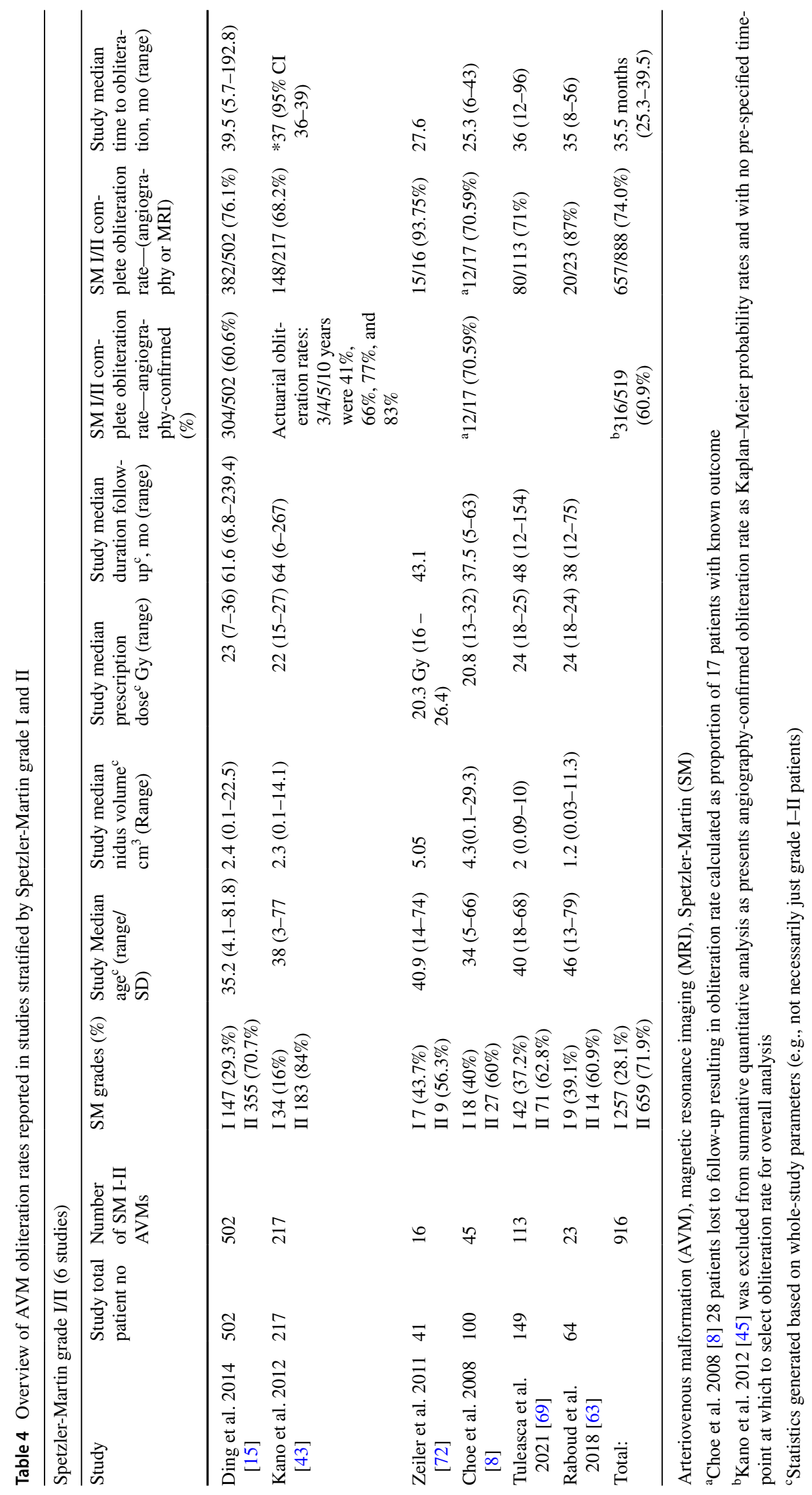




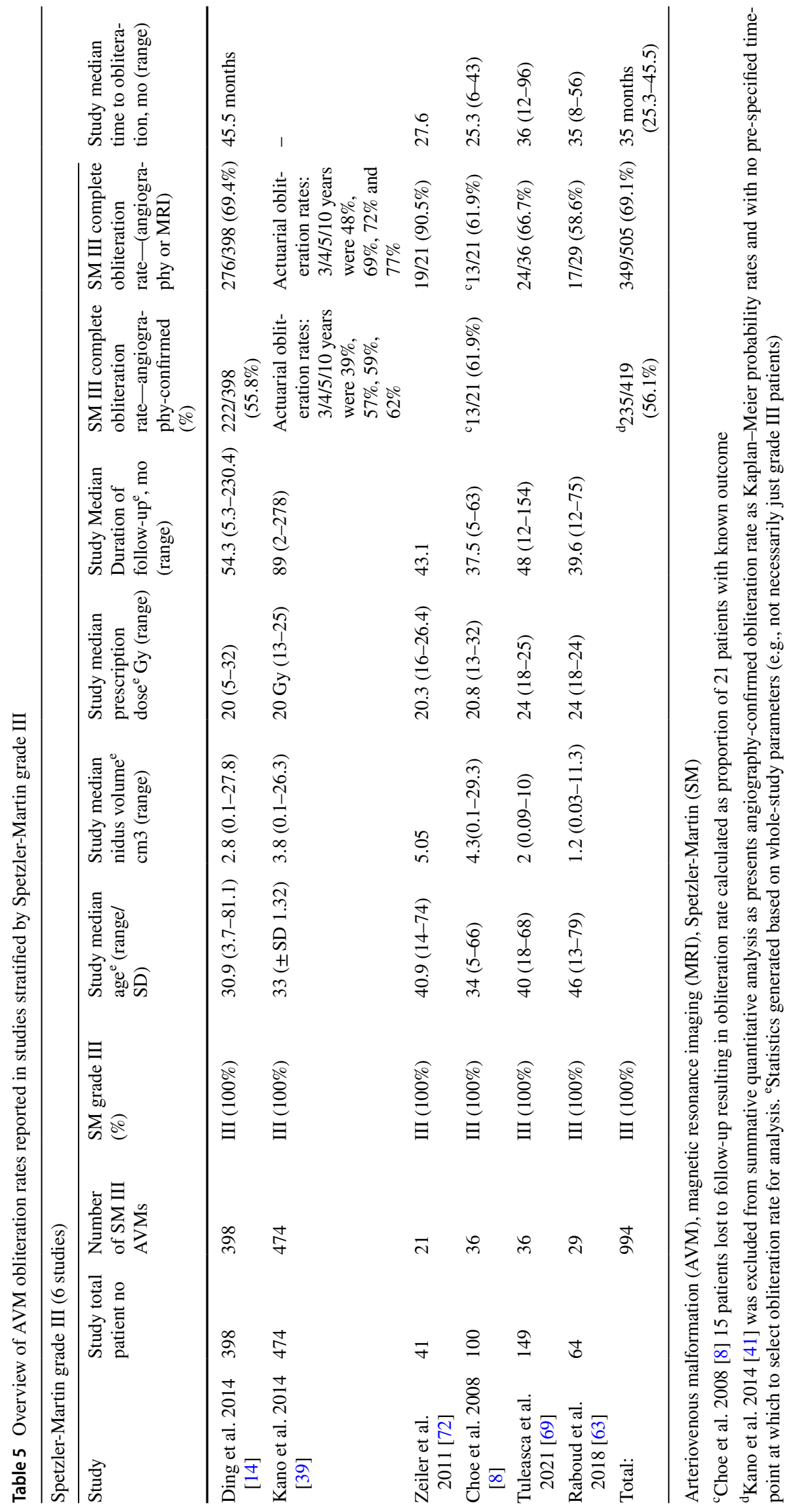




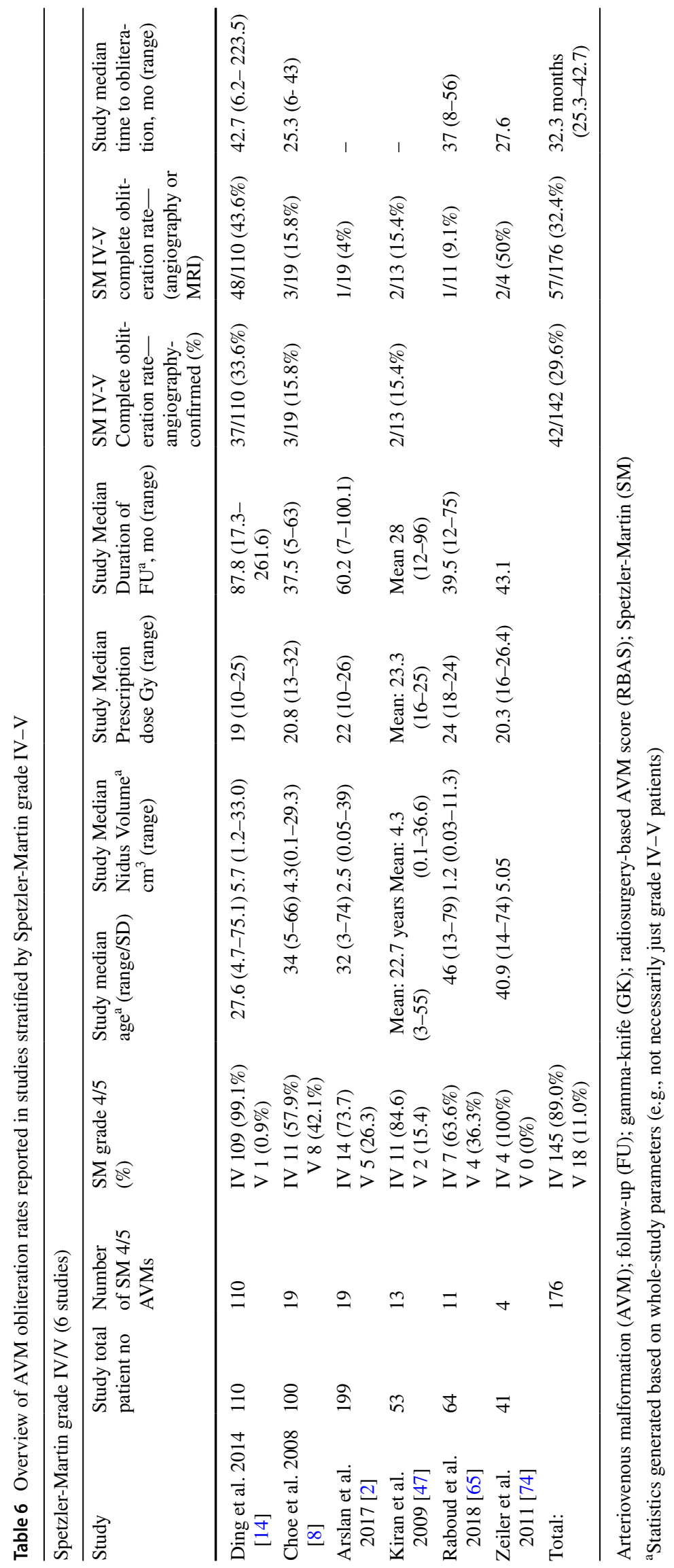


Study

Arslan et al. 2017 [2]

Bir et al. 2015 [4]

Bose et al. 2015 [5]

Chang et al. 2000 [6]

Chen et al. 2018 [7]

Choe et al. 2008 [8]

Ding et al. 2014 [14]

Ding et al. 2014 [15]

Ding et al. 2014 [16]

Ditty et al. 2017 [18]

Franzin et al. 2013 [24]

Han et al. 2008 [31]

Hasegawa et al. 2018 [32]

Hirschmann et al. 2019 [35]

Hu et al. 2020 [36]

Izawa et al. 2005 [39]

Kano et al. 2014 [41]

Kano et al. 2012 [43]

Kano et al. 2012 [44]

Kano et al. 2012 [45]

Kim BS et al. 2019 [46]

Kiran et al. 2009 [47]

Liscák et al.2007 [49]

Matsunaga et Shuto. 2014 [51]

Missios et al. 2014 [52]

Nicolato et al. 2002 [54]

Orio et al. 2006 [56]

Pan et al. 2000 [57]

Parkhutik et al. 2013 [58]

Pollock et al. 2016 [64] (1990-2009)

Raboud et al. 2018 [65]

Tuleasca et al. 2021 [71]

Zeiler et al. 2011 [74]

Zhao et al. 2008 [75]
Event, $\mathbf{n}$ Total patients Prevalence (\%)

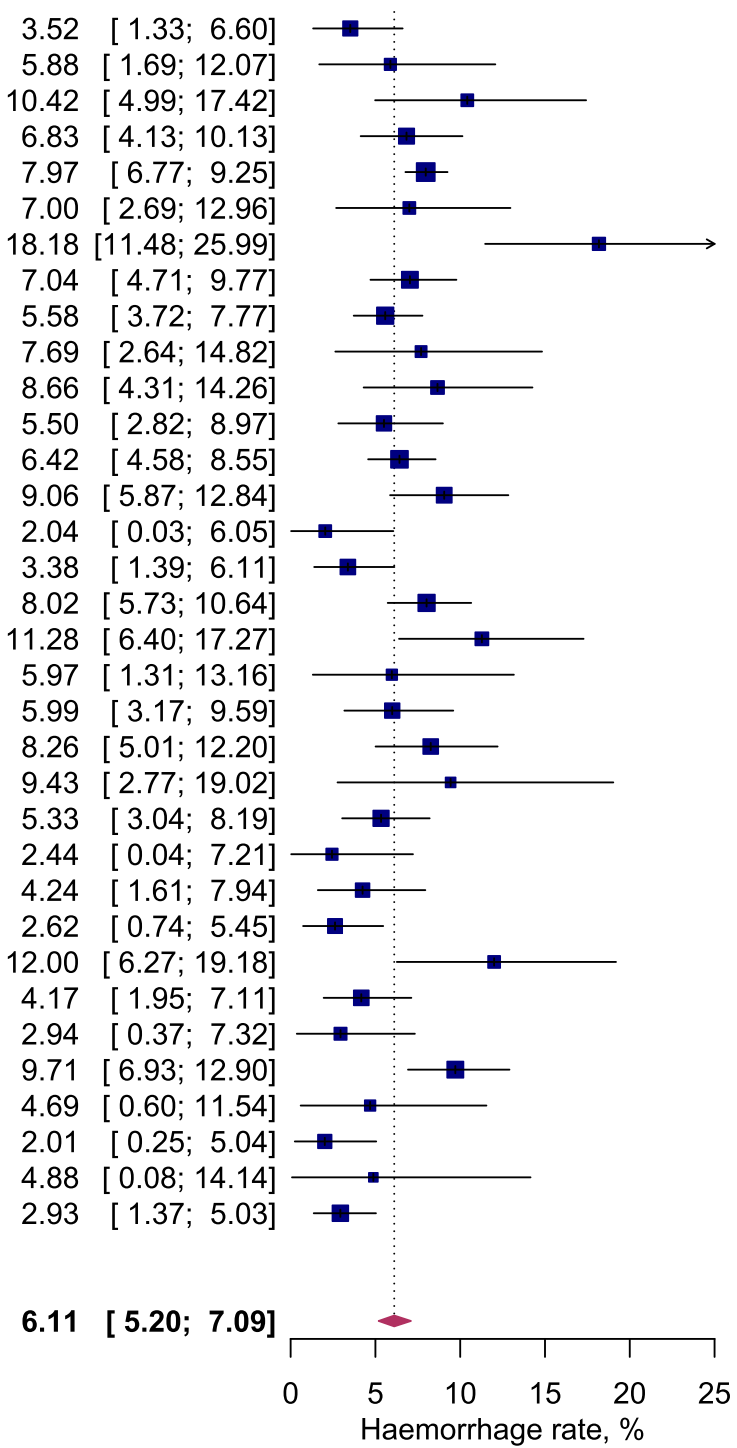

199
85
96
278
1845
100
110
398
502
78
127
218
592
265
98
237
474
133
67
217
230
53
300
82
165
191
100
240
102
381
64
149
41
341

96

278

1845

100

398

502

78

127
218

592

265

98
237

474

133

67
217

230

53
300

82

165

191

240

102

381

64
149

$\begin{array}{rr}2 & 41 \\ 10 & 341\end{array}$
95\% CI Post-GKRS Haemorrhage Rate
Random effects model

Heterogeneity: $I^{2}=63 \%, \tau^{2}=0.0018, \chi_{33}^{2}=88.67(p<0.01)$ 


\section{Study}

Arslan et al. 2017 [2]

Bir et al. 2015 [4]

Chang et al. 2000 [6]

Chen et al. 2018 [7]

Choe et al. 2008 [8]

Ding et al. 2014 [14]

Ding et al. 2014 [15]

Ding et al. 2014 [16]

Franzin et al. 2013 [24]

Han et al. 2008 [31]

Izawa et al. 2005 [39]

Kano et al. 2014 [41]

Kano et al. 2012 [43]

Kano et al. 2012 [44]

Kano et al. 2012 [45]

Kim BS et al. 2019 [46]

Kiran et al. 2009 [47]

Liscák et al.2007 [49]

Matsunaga et Shuto. 2014 [51]

Nicolato et al. 2002 [54]

Orio et al. 2006 [56]

Pan et al. 2000 [57]

Pollock et al. 2016 [64] (1990-2009)

Raboud et al. 2018 [65]

Tuleasca et al. 2021 [71]

Zeiler et al. 2011 [74]

Zhao et al. 2008 [75]
Event, $\mathbf{n}$ Total patients Prevalence (\%)

95\% CPost-GKRS Permanent RIC Rate
Random effects model

Heterogeneity: $I^{2}=77 \%, \tau^{2}=0.0034, \chi_{26}^{2}=112.43(p<0.01)$

199
85
278
1845
76
110
334
414
127
157
237
474
133
67
217
264
53
300
82
191
100
242
381
64
149
41
341

85

278

1845

76

110
334

414

127

157

237

474

133

67

217

264

53

300

82
191

100

242

381

64

41

341

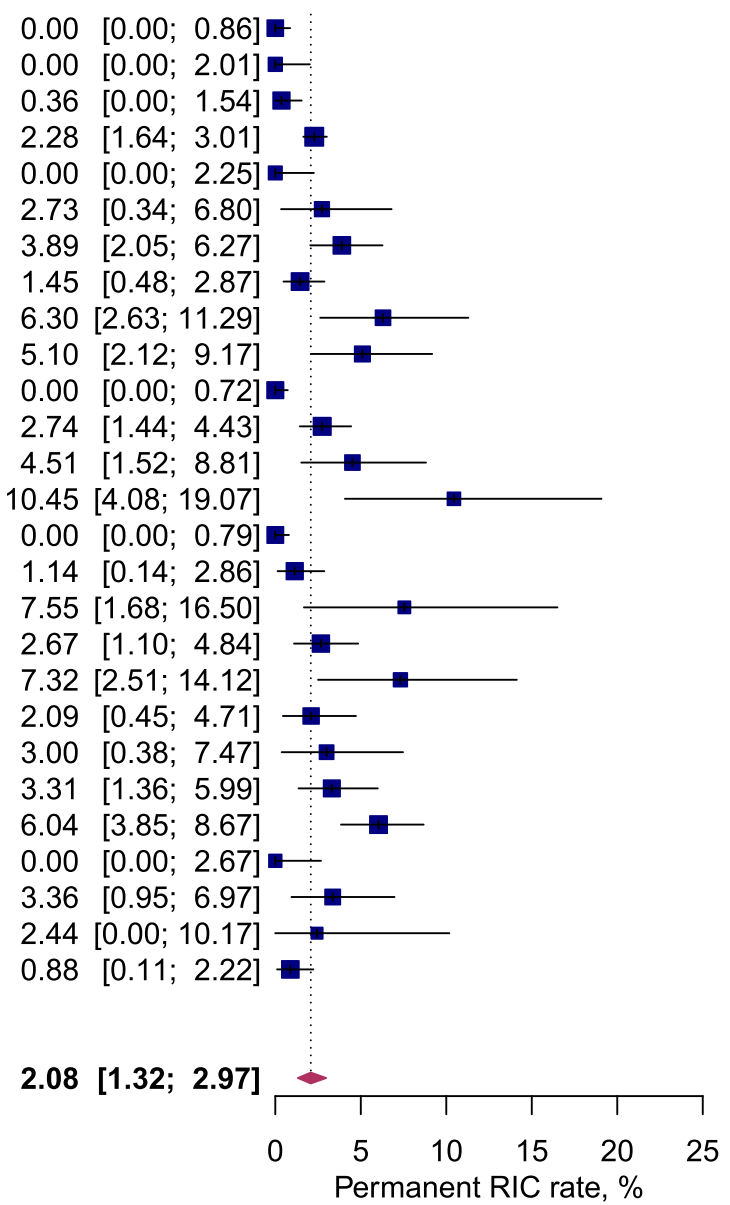

Fig. 3 Forest plot: pooled estimates of post-GKRS permanent RICs rate. Arteriovenous malformation (AVM), gamma-knife radiosurgery (GKRS), radiation-induced changes (RICs)

(range, 0-14.4\%) of patients. Case-related deaths (secondary to ICH or RIC) occurred in 88 (2.1\%) patients. New-onset or increased frequency of seizures occurred in a median of $1.8 \%$ (range, $0-11.8 \%$ ) of patients.

Annual post-GKRS haemorrhage rate was 1.38\% (95\% CI 1.28-1.50). Annual case-fatality rate was $0.46 \%$ (95\% CI $0.37-0.57)$. Annual all-cause fatality rate (AVM/non-AVM related) was $0.67 \%$ (95\% CI 0.58-0.76). All annual incidence of outcomes were calculated per 100 person-years of follow-up over the duration of follow-up described in included studies.

Complete nidus obliteration, confirmed on angiography imaging, was achieved in 56.7\% (3092/5450) of patients in 21 cohorts, at the end of follow-up after single-stage Gamma knife treatment [5-8, 14-16, 24, 31, 32, 36, 39, 46, 47, 49, $51,52,54,57,58,65]$. Overall nidus obliteration, confirmed with either angiography or MRI imaging, was achieved in $67.8 \%$ (4605/6792) of patients in 29 cohorts, at the end of follow-up after single-stage Gamma knife treatment [2, 4-8,
14-16, 18, 24, 31, 32, 36, 39, 46, 47, 51, 52, 54, 56-58, 64, 65, 71, 74, 75]. Table 3 outlines AVM GKRS obliteration outcomes. Median time to complete nidus obliteration was 35.4 months following GKRS (95\% CI 32.5-38.3). Six studies stratified their obliteration outcomes for AVMs of Spetzler-Martin grades I-II, totalling 916 AVMs (study median margin dose $22.5 \mathrm{~Gy}$ and median duration followup 45.5 months) [8, 16, 45, 52, 65, 71]. Complete nidus obliteration rate was $74.0 \%$ (657/888) (Table 4). Six studies stratified their obliteration outcomes for AVMs of SpetzlerMartin grade III, totalling 994 AVMs (study median margin dose $20.6 \mathrm{~Gy}$ and median duration follow-up 45.6 months) $[8,15,41,52,65,71]$. Complete nidus obliteration rate was $69.1 \%$ (349/505) (Table 5). Six studies stratified their obliteration outcomes for AVMs of Spetzler-Martin grade IV-V, totalling 176 AVMs (study median margin dose 21.4 Gy and median duration follow-up 41.3 months) $[2,8,14,47,52$, 65]. Complete nidus obliteration rate was $32.4 \%$ (57/176) (Table 6). We were unable to consistently and reliably 
quantify clinical outcomes according to Spetzler-Martin grade because most studies did not stratify their reporting of outcomes by SM grade. We were unable to consistently and reliably quantify outcomes according to RBAS score because studies did not stratify their reporting of outcomes by the RBAS score, of which the median was 1.42 (IQR $1.2-1.5)$.

\section{Synthesis of results}

On pooled analysis, post-GKRS ICH rate was $6.1 \%$ (95\% CI $5.2-7.1 \%, I^{2}=63 \%$ ) (Fig. 2); permanent symptomatic RIC rate was $2.1 \%$ (95\% CI $1.3-2.9 \%, I^{2}=77 \%$ ) (Fig. 3); transient symptomatic RIC rate was 5.2\% (95\% CI 3.7-6.7\%, $I^{2}=76 \%$ ) (Fig. 4); and case-fatality rate was $2.3 \%$ (95\% CI $\left.1.7-3.2 \%, I^{2}=54 \%\right)$.

At the end of follow-up after single-session GKRS, 60.5\% (95\% CI 54.2-66.7\%, $I^{2}=95 \%$ ) of AVMs were confirmed obliterated on angiography imaging and $69.7 \%$ (95\% CI $65.9-73.5 \%, I^{2}=91 \%$ ) of AVMs were confirmed obliterated on either angiography-or-MRI imaging (Figs. 5 and 6). Table 7 summarise the results of meta-analysis.

Sensitivity analysis identified one outlier within the haemorrhage pooled analysis [14]. Excluding this outlier yielded a new pooled estimate value of $6.3 \%$ (95\% CI $5.53-7.27 \%, I^{2}=51 \%$ ). One potential outlier was identified within the transient symptomatic RIC pooled analysis [46]. Excluding the outlier, yielded a new pooled estimate value of $4.98 \%$ (95\% CI $3.8-6.3 \%, I^{2}=66 \%$ ).

Cohorts with higher proportions of AVMs with strictly deep venous drainage $(p=0.005)$ and eloquent location $(p=0.026)$ were associated with higher haemorrhage rates. The chance of complete AVM obliteration was higher in more recent cohorts $(p=0.021)$ with younger patients $(p=0.018)$ or AVMs with deep venous drainage $(p=0.035)$. A higher risk of both transient and permanent symptomatic RIC was associated with cohorts with higher proportions of AVMs in deep locations $(p=0.002$ and 0.005). Appendix 8 summarises moderator analysis performed for primary outcomes.

\section{Publication bias}

Five funnel plots (Appendix 9) illustrate no significant evidence of publication bias. Egger's regression test for funnel plot asymmetry values: $0.77,0.89,0.27,0.19$ and 0.10 for haemorrhage, transient symptomatic RIC, permanent symptomatic RIC, angiography-confirmed and overall obliteration, respectively.

\section{Discussion}

We have systematically reviewed the three primary outcomes defining successful AVM GKRS: rate of AVM obliteration, chance of post-GKRS ICH and risk of radiationinduced complications, to establish a comprehensive and contemporary risk: benefit profile for AVM GKRS.

Starke et al. previously reported on 2236 AVMs treated with GKRS between 1988 and 2013, with mean volume $4.3 \mathrm{~cm}^{3}, 20.5 \mathrm{~Gy}$ margin dose and follow-up of 7 years. This multi-centre study reported a comparable overall nidus obliteration rate of $64.7 \%$, haemorrhage rate of $7.4 \%$ with annual incidence of $1.1 \%$, whilst symptomatic RICs were transient in $6.7 \%$ and permanent in $2.7 \%$ of patients at the end of follow-up [69]. The most contemporary systematic review of SRS for brain AVMs was performed by van Beijnum et al. in 2013, investigating the outcomes following treatment of 9436 AVMs across multiple interventions (surgery, SRS or embolisation). They reported a median post-SRS haemorrhage rate of $5.8 \%$ and an annual ICH and case-related fatality rate of 1.7 and 0.5 per 100 person-years [72].

Generally, nidus obliteration can be achieved in $65-85 \%$ of patients after a 3-5 year latency period [20, 23, 60, 61, 69]. Of note, van Beijnum et al. reported a significantly lower median angiography-confirmed obliteration rate of $38 \%$ following AVM SRS [72]. This can partly be reasoned to their strict calculation of obliteration rate, calculated as a proportion of patients confirmed obliterated as a proportion of all SRS-treated patients, which did not account for patients without complete angiography radiological followup to confirm obliteration or those patients lost to followup. Also, obliteration was calculated from 69 SRS studies (GKRS-modality: 22/69) with a shorter median follow-up of 35 months. In our pooled analysis, $60.5 \%$ of patients achieved angiography-confirmed obliteration and overall nidus obliteration rate was $69.7 \%$ with a median time to obliteration of 35.4 months after initial radiosurgical intervention. Whilst realisation of nidus obliteration on neuroimaging occurs at relatively varying intervals due to differences in the intervals of radiological follow-up, our median study follow-up (60 months) is a sufficient duration, we believe, to accommodate this post-GKRS latency period whilst supporting the validity of our findings.

On behalf of the International Stereotactic Radiosurgery Society (ISRS), a systematic review was performed to establish SRS practice guidelines for SM I/II AVMs [30]. Of 1102 SM I/II AVMs (78\% SM II, median margin dose $23 \mathrm{~Gy}$, volume $2.4 \mathrm{~cm}^{3}$ ), overall reported obliteration rate was $80 \%$. Of 888 SM I/II AVMs (72\% SM II) in our study, 74\% achieved obliteration. Both findings highlight that appropriately selected, low-grade AVMs can expect a significant chance of successful outcome. 


\section{Study}

Arslan et al. 2017 [2]

Bir et al. 2015 [4]

Chang et al. 2000 [6]

Chen et al. 2018 [7]

Choe et al. 2008 [8]

Ding et al. 2014 [14]

Ding et al. 2014 [15]

Ding et al. 2014 [16]

Han et al. 2008 [31]

Kano et al. 2014 [41]

Kano et al. 2012 [43]

Kano et al. 2012 [44]

Kano et al. 2012 [45]

Kim BS et al. 2019 [46]

Kiran et al. 2009 [47]

Matsunaga et Shuto. 2014 [51]

Nicolato et al. 2002 [54]

Pan et al. 2000 [57]

Raboud et al. 2018 [65]

Zeiler et al. 2011 [74]

Zhao et al. 2008 [75]
Event, n Total patients Prevalence (\%)

95\% CI Post-GKRS Transient RIC Rate
Random effects model

Heterogeneity: $I^{2}=76 \%, \tau^{2}=0.0032, \chi_{20}^{2}=83.73(p<0.01)$

199
85
278
1845
76
110
334
414
157
474
133
67
217
264
53
82
191
242
64
59
341

85

278

845

76

110

334

414

157

474

33

67

217

64

53

82

91

42

54

341

\section{(1)}

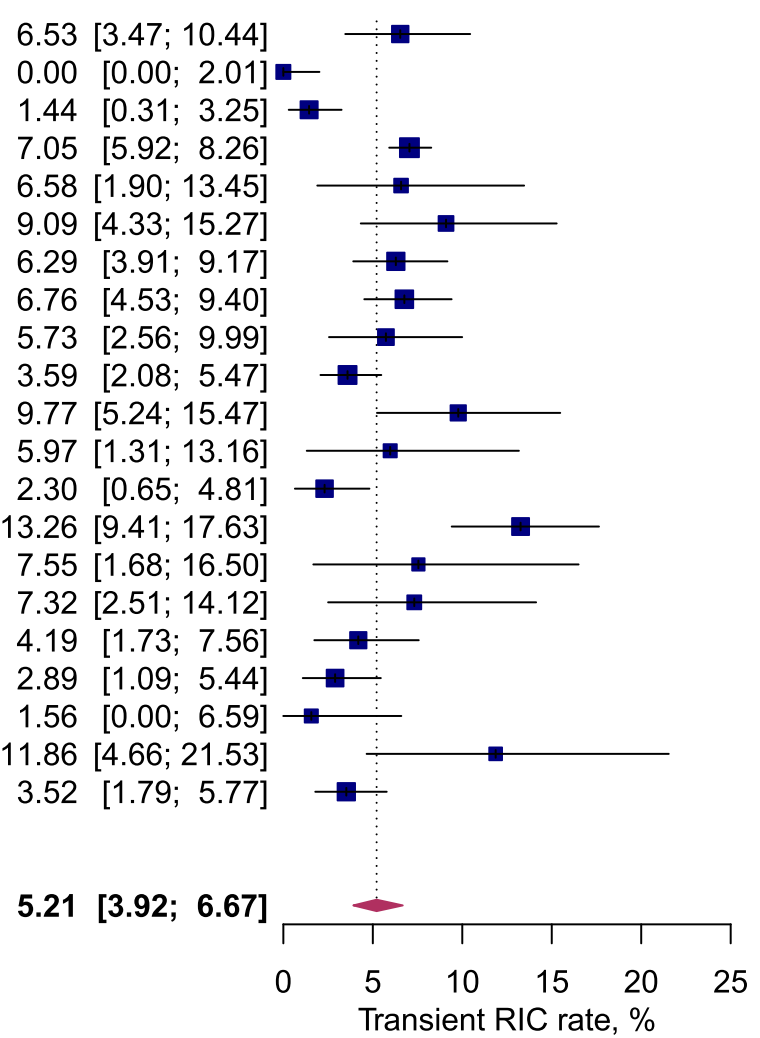

Fig. 4 Forest plot: pooled estimates of post-GKRS transient RICs rate. Arteriovenous malformation (AVM), gamma-knife radiosurgery (GKRS), radiation-induced changes (RICs)

Spetzler-Martin grade III AVMs are angioarchitecturally heterogeneous lesions, straddling the boundary between low grade (I-II) AVMs, which favour intervention with microsurgical resection, and high grade (IV-V) AVMs, which favour conservative management. Our findings suggest grade III AVMs experience a reasonable risk-to-benefit profile following GKRS; of 505 AVMs, 69\% achieved obliteration.

Whilst our pooled and SM-stratified obliteration values entice direct comparisons with obliteration outcomes following surgical resection, caution is warranted as patient selection for GKRS versus surgical resection is undoubtedly to have been influenced by individual patient and AVM features which were not available for further detailed analysis.

Previous studies have reported on patient, AVM and treatment factors associated with the development of RICs, of which, increasing radiation dose and irradiated AVM volume, have been well established [5, 13, 17, 40]. Kano et al. investigated the incidence of and treatment parameters that contributed to the development of RICs following AVM GKRS. Further, 775 patients (median volume $3.6 \mathrm{~cm}^{3}$ and dose $20 \mathrm{~Gy}$ ) underwent single-stage GKRS with $\geq 2$ years of follow-up, with reported symptomatic and permanent RIC rates of $7.1 \%$ and $3 \%$, respectively. Increased AVM volume,
12-Gy volume, higher margin dose and deep location were associated with a higher rate of developing symptomatic RICs [40]. In our meta-analysis, we found no significant association between either median study margin dose or AVM volume and the development of transient symptomatic ( $p=0.45$ and 0.43 ) or permanent RICs ( $p=0.17$ and 0.19$)$. We believe that this may be due to lack of individual patient data, differences in patient selection and variations in GKRS treatment protocols among included studies; all of which precluded a sufficiently rigorous analysis of the relationship among study nidus volume, margin dose, and symptomatic RIC occurrence. Furthermore, this dose-volume relationship has been further refined to specify the '12-Gray volume', the volume of brain tissue receiving radiation dose of $12 \mathrm{~Gy}$ or more, which is strongly correlated with the risk of RICs [20, 55]. Interestingly, only one study in our review [64] referred to the 12-Gy volume in their analysis of RIC outcomes. Studies suggest these dose-volume relationships are more strongly associated with the development of post-SRS RICs and less influential for the occurrence of symptomatic RICs [29, 55].

One AVM angioarchitectural feature consistently reported to be associated with the development of symptomatic RICs 


\section{Study}

Arslan et al. 2017 [2]

Bir et al. 2015 [4]

Bose et al. 2015 [5]

Chang et al. 2000 [6]

Chen et al. 2018 [7]

Choe et al. 2008 [8]

Ding et al. 2014 [14]

Ding et al. 2014 [15]

Ding et al. 2014 [16]

Ditty et al. 2017 [18]

Franzin et al. 2013 [24]

Han et al. 2008 [31]

Hasegawa et al. 2018 [32]

Hu et al. 2020 [36]

Izawa et al. 2005 [39]

Kim BS et al. 2019 [46]

Kiran et al. 2009 [47]

Liscák et al.2007 [49]

Matsunaga et Shuto. 2014 [51]

Missios et al. 2014 [52]

Nicolato et al. 2002 [54]

Pan et al. 2000 [57]

Parkhutik et al. 2013 [58]

Pollock et al. 2016 [64] (1990-1999)

Pollock et al. 2016 [64] (1999-2009)

Raboud et al. 2018 [65]

Tuleasca et al. 2021 [71]

Zeiler et al. 2011 [74]

Zhao et al. 2008 [75]
Event, $\mathbf{n}$ Total patients Prevalence (\%)

95\% Cl Angio/MRI Obliteration Rate

\section{Random effects model}

Heterogeneity: $I^{2}=91 \%, \tau^{2}=0.0092, \chi_{28}^{2}=307.36(p<0.01)$

$\begin{array}{rr}141 & 199 \\ 67 & 85 \\ 39 & 54 \\ 101 & 128 \\ 1147 & 1845 \\ 28 & 48 \\ 48 & 110 \\ 276 & 398 \\ 382 & 502 \\ 34 & 59 \\ 72 & 104 \\ 131 & 183 \\ 391 & 592 \\ 63 & 98 \\ 130 & 237 \\ 164 & 264 \\ 14 & 19 \\ 222 & 300 \\ 65 & 82 \\ 70 & 165 \\ 111 & 131 \\ 115 & 131 \\ 50 & 82 \\ 130 & 160 \\ 168 & 221 \\ 39 & 64 \\ 104 & 149 \\ 36 & 41 \\ 267 & 341\end{array}$

341 $\begin{array}{ll}70.85 & {[64.54 ; 77.17]} \\ 78.82 & {[70.14 ; 87.51]} \\ 72.22 & {[60.28 ; 84.17]} \\ 78.91 & {[71.84 ; 85.97]} \\ 62.17 & {[59.96 ; 64.38]} \\ 58.33 & {[44.39 ; 72.28]} \\ 43.64 & {[34.37 ; 52.90]} \\ 69.35 & {[64.82 ; 73.88]} \\ 76.10 & {[72.36 ; 79.83]} \\ 57.63 & {[45.02 ; 70.24]} \\ 69.23 & {[60.36 ; 78.10]} \\ 71.58 & {[65.05 ; 78.12]} \\ 66.05 & {[62.23 ; 69.86]} \\ 64.29 & {[54.80 ; 73.77]} \\ 54.85 & {[48.52 ; 61.19]} \\ 62.12 & {[56.27 ; 67.97]} \\ 73.68 & {[53.88 ; 93.48]} \\ 74.00 & {[69.04 ; 78.96]} \\ 79.27 & {[70.49 ; 88.04]} \\ 42.42 & {[34.88 ; 49.97]} \\ 84.73 & {[78.57 ; 90.89]} \\ 87.79 & {[82.18 ; 93.39]} \\ 60.98 & {[50.42 ; 71.53]} \\ 81.25 & {[75.20 ; 87.30]} \\ 76.02 & {[70.39 ; 81.65]} \\ 60.94 & {[48.98 ; 72.89]} \\ 69.80 & {[62.43 ; 77.17]} \\ 87.80 & {[77.79 ; 97.82]} \\ 78.30 & {[73.92 ; 82.67]}\end{array}$
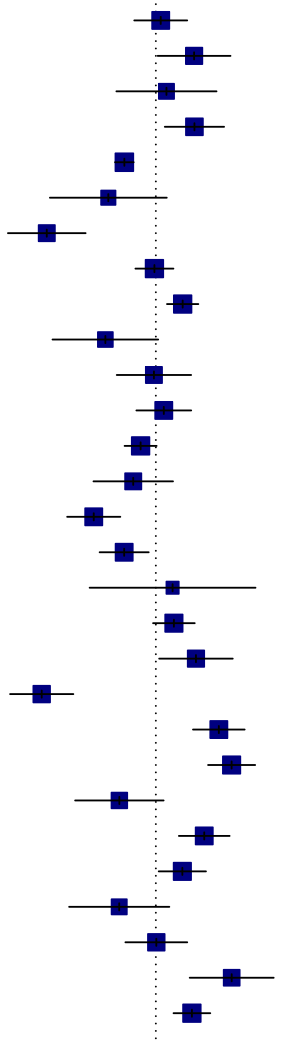

$69.68[65.89 ; 73.48]$

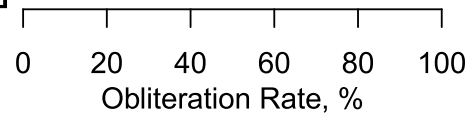

Fig. 5 Forest plot: pooled estimates of post-GKRS angiography-or-MRI confirmed obliteration rate. Arteriovenous malformation (AVM), gamma-knife radiosurgery (GKRS), magnetic resonance imaging (MRI)

is deep location, more specifically, the brainstem [19, 21, 22, 61]. This was confirmed in our findings for both transient $(p=0.002)$ and permanent symptomatic RICs $(p=0.005)$ and is reflected in the RBAS grading system where deep location confers a higher risk feature associated with poorer outcome post-GKRS [61, 62].

The relative risk of AVM haemorrhage during the latency period between radiosurgery and obliteration versus an untreated AVM's natural history remains a topic of debate [12]. In comparison to the generally accepted $2-4 \%$ natural haemorrhage rate of untreated AVMs [1], decreased, unchanged or increased rates of haemorrhage after radiosurgery have been reported $[27,50,59]$. In our pooled analysis, the annual haemorrhage rate following GKRS was $1.4 \%$. This suggests radiosurgical intervention may afford partial protection from AVM rupture during the latency interval before nidus obliteration; however, we cannot definitively exclude that the decline in haemorrhage rate following
GKRS is not part of the natural course of the disease or due to selection bias of included studies.

Further, in our analysis, we were unable to determine whether pre-GKRS AVM rupture status, yielded a significantly lower or higher post-GKRS haemorrhage risk as (1) the majority of studies did not stratify haemorrhage rate by rupture status, and (2) we did not have access to individual patient data to perform rigorous sub-group analysis within individual cohorts. Yen et al. [73] evaluated the rates of preand post-GKRS haemorrhage in a cohort of 1204 AVMs. The annual AVM haemorrhage risk from birth to radiosurgery, assuming patients are at risk of haemorrhage from birth, was $2.0 \%$ for the entire cohort and $3.7 \%$ for AVMs with prior haemorrhage. Post-GKRS, the annual haemorrhage risk until obliteration was $2.5 \%$, stratified as $2.8 \%$ and $2.2 \%$ for AVMs with and without prior haemorrhage. Kano et al. [42] reported on a cohort of 407 ruptured AVMs. The annual haemorrhage rate between birth and radiosurgery was 


\section{Study}

Bose et al. 2015 [5]

Chang et al. 2000 [6]

Chen et al. 2018 [7]

Choe et al. 2008 [8]

Ding et al. 2014 [14]

Ding et al. 2014 [15]

Ding et al. 2014 [16]

Franzin et al. 2013 [24]

Han et al. 2008 [31]

Hasegawa et al. 2018 [32]

Hu et al. 2020 [36]

Izawa et al. 2005 [39]

Kim BS et al. 2019 [46]

Kiran et al. 2009 [47]

Liscák et al.2007 [49]

Matsunaga et Shuto. 2014 [51]

Missios et al. 2014 [52]

Nicolato et al. 2002 [54]

Pan et al. 2000 [57]

Parkhutik et al. 2013 [58]

Raboud et al. 2018 [65]
Event, $\mathbf{n}$ Total patients Prevalence (\%)

95\% Cl Angio-only Obliteration Rate

\section{Random effects model}

Heterogeneity: $I^{2}=95 \%, \tau^{2}=0.0194, \chi_{20}^{2}=429.11(p<0.01)$

54
128
1845
48
110
398
502
90
119
592
98
237
264
19
300
82
165
131
131
82
55

54

128

$896 \quad 1845$

$\begin{array}{rr}28 & 48 \\ 37 & 110\end{array}$

222

304

54

79

391

43

130

115

14

222

41

70

111

115

50

30
398

502

90

592

98

237

264

19

82

65

131

82

55
72.22 [60.28; 84.17]

$78.91[71.84 ; 85.97]$

$48.56[46.28 ; 50.84]$

$58.33[44.39 ; 72.28]$

$33.64[24.81 ; 42.47]$

$55.78[50.90 ; 60.66]$

$60.56[56.28 ; 64.83]$

$60.00[49.88 ; 70.12]$

66.39 [57.90; 74.87]

$66.05[62.23 ; 69.86]$

$43.88[34.05 ; 53.70]$

54.85 [48.52; 61.19]

$43.56[37.58 ; 49.54]$

$73.68 \quad[53.88 ; 93.48]$

74.00 [69.04; 78.96]

$50.00[39.18 ; 60.82]$

$42.42[34.88 ; 49.97]$

84.73 [78.57; 90.89]

87.79 [82.18; 93.39]

$60.98[50.42 ; 71.53]$

$54.55[41.39 ; 67.70]$
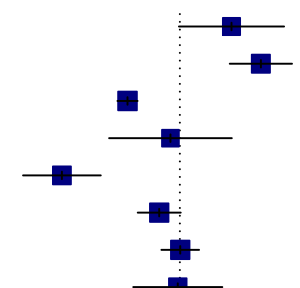

$+\frac{1}{i}$
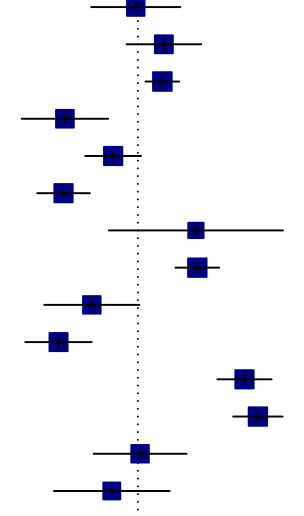

$60.47[54.20 ; 66.74]$

Fig. 6 Forest plot: pooled estimates of post-GKRS Angiography-only confirmed obliteration rate. Arteriovenous malformation (AVM), gammaknife radiosurgery (GKRS), magnetic resonance imaging (MRI)

$3.4 \%$, reducing to $1.3 \%$ following radiosurgical intervention. Overall, it appears GKRS reduces the haemorrhage risk of AVMs before obliteration, an attribute that may be more pronounced in patients who present with haemorrhage.

Cyst formation (CF) is an uncommon complication following SRS. In our review, 15 studies totalling 3446 patients reported a pooled incidence of $2 \%$. This is approximated by the only comprehensive analysis of CF following GKRS by Ilyas et al., reporting a pooled CF rate of $2.9 \%$ in 2562 patients following GKRS, with a mean latency period of 6.5 years from time of GKRS to cyst detection [37]. A shorter median study follow-up (5 years) in our study, may partly explain a slightly reduced CF incidence. Reassuringly, in most cases, cysts are managed conservatively with relative success, especially if they are asymptomatic, radiologically stable or do not exert significant local mass effect [12].

\section{Limitations}

The strengths of this review include adherence to PRISMA guidelines, its pre-specified protocol and formal validated risk-of-bias assessment. Studies included in this review generally followed a similar AVM GKRS treatment and
Table 7 Meta-analysis pooled estimates of outcomes postGKRS for AVMs

\begin{tabular}{lcc}
\hline Outcome parameter & Summary estimate (95\% CI) & $I^{2}$ \\
\hline Haemorrhage & $6.11 \%(5.20-7.09)$ & $\mathbf{6 3 \%}$ \\
Transient Symptomatic RICs & $5.21 \%(3.92-6.67)$ & $\mathbf{7 6 \%}$ \\
Permanent Symptomatic RICs & $2.08 \%(1.32-2.97)$ & $\mathbf{7 7 \%}$ \\
Obliteration (Angiography confirmed) & $60.47 \%(54.20-66.74)$ & $\mathbf{9 5 \%}$ \\
Obliteration (Angiography or MRI-confirmed) & $69.68 \%(65.89-73.48)$ & $\mathbf{9 1 \%}$ \\
Mortality (2 $2^{\circ}$ to ICH/RICs) & $2.32 \%(1.66-3.24)$ & $\mathbf{5 3 . 7 \%}$ \\
\hline
\end{tabular}

Arteriovenous malformation (AVM), gamma-knife radiosurgery (GKRS), intracranial haemorrhage (ICH), magnetic resonance imaging (MRI), radiation-induced changes (RIC) 
follow-up protocol, of which the median length of followup across all studies was approximately 5 years.

In terms of limitations, the included studies were all nonrandomised, mostly retrospective and at moderate risk of bias. In most analyses, heterogeneity was present and substantial, with the highest $I^{2}$ values found in cohorts reporting obliteration outcomes. We are aware that certain studies may have been excluded whilst strictly adhering to our inclusion criteria which required outcomes data on obliteration, haemorrhage and RICs cumulatively or excluded solely due to English language restriction (Appendix 3, 4).

Most studies (29) in this review reported an aggregated angiography or MRI confirmed obliteration rate, some in addition or as an alternative to an angiography-only confirmed obliteration rate. Whilst MR-imaging has been shown to exhibit $77-85 \%$ sensitivity and $89-95 \%$ specificity for AVM obliteration detection $[48,63]$, there is a risk of incorrectly assuming AVMs to be obliterated by MRI at the time of assessment with subsequent over-estimation of the true nidus obliteration rate, especially when obliteration status is confirmed solely using MRI. False-positive nidal obliteration according to MRI can be detrimental to the patient because any residual arteriovenous shunting represents a persistent haemorrhage risk with the subsequent possibility of adverse outcome. In our pooled analysis, $60.5 \%$ of patients achieved angiography-confirmed obliteration whilst overall nidus obliteration rate, confirmed with either angiography or MRI, was $69.7 \%$. Our findings for SM-stratified obliteration rates also illustrated a consistent and clinically significant incongruence between rates of obliteration confirmed by angiography or MRI and obliteration confirmed by angiography alone. Whilst it can be appreciated why some patients may choose to forgo DSA, for example due to its invasiveness, risk of procedural complications or false reassurance from the absence of AVM or GKRS-related symptoms, ultimately it remains the gold standard of accurately assessing AVM obliteration status and should remain the critical and definitive determinant of nidal obliteration in any post-GKRS imaging protocol $[10,33]$.

In this review, we obtained aggregate patient, AVM and outcome data with a tendency for studies to report on the whole patient cohort with limited further sub-group analysis. Very few studies stratified outcomes by individual patient and AVM features, e.g. by location, AVM volume, margin dose or SM grade, which have been wellestablished to affect radiosurgical outcomes. Further, the reporting of a clinically heterogeneous cohort of patients with AVMs is likely to contribute to heterogenous pooled estimates of outcomes, as illustrated in our findings. Interpreting these summary outcome estimates, without robust sub-group analysis can mitigate the generalisability of our findings for individual patients and future AVM treatment decision-making.
Standardised prospective multi-centre recording of patient, AVM and treatment characteristics and reporting of outcomes is needed to be certain of individual AVM risks and benefit prediction. Stratifying clinical outcomes further by AVM and pre-specified treatment subgroups will contribute to the selection of a more homogenous set of AVMs from which meaningful comparisons of outcomes can be made and valid conclusions can be drawn.

\section{Conclusion}

Gamma knife radiosurgery is a safe and effective treatment option for cerebral AVMs. Appropriately selected patients can expect a significant chance of successful obliteration coupled with minimal risks of haemorrhage and radiation-induced complications. Future studies would be strengthened by attempting to report on a homogenous set of study participants, in terms of pre-specified patient, AVM angioarchitectural or treatment parameters, which would allow for a more conclusive risk: benefit profile of AVM GKRS to be established.

Supplementary Information The online version contains supplementary material available at https://doi.org/10.1007/s10143-022-01751-1.

Author contribution All authors (MC, AV, CSH, CT, PG) contributed to this manuscript. MC and AV are joint first-authors contributing equally to the manuscript.

Data availability The analysis for this study is based on published results from individual studies. See Appendix; all extracted data from individual studies, code used for performing the meta-analyses and sensitivity analysis can be made available upon reasonable request to the corresponding author.

Code availability The code used for performing the meta-analyses and sensitivity analysis can be made available upon reasonable request to the corresponding author.

\section{Declarations}

Ethics approval Not required.

Consent to participate Not applicable.

Consent for publication Not applicable.

Conflict of interest CSH is funded by a NIHR Academic Clinical Lectureship, a CRUK Pioneer Award, Academy of Medical Sciences Starter Grant, and by a National Brain Appeal Innovation Award. The authors declare no conflict of interest.

Open Access This article is licensed under a Creative Commons Attribution 4.0 International License, which permits use, sharing, adaptation, distribution and reproduction in any medium or format, as long as you give appropriate credit to the original author(s) and the source, 
provide a link to the Creative Commons licence, and indicate if changes were made. The images or other third party material in this article are included in the article's Creative Commons licence, unless indicated otherwise in a credit line to the material. If material is not included in the article's Creative Commons licence and your intended use is not permitted by statutory regulation or exceeds the permitted use, you will need to obtain permission directly from the copyright holder. To view a copy of this licence, visit http://creativecommons.org/licenses/by/4.0/.

\section{References}

1. Al-Shahi R, Bhattacharya JJ, Currie DG et al (2003) Prospective, population-based detection of intracranial vascular malformations in adults: the Scottish Intracranial Vascular Malformation Study (SIVMS). Stroke 34(5):1163-1169. https://doi.org/10.1161/01. STR.0000069018.90456.C9

2. Arslan I, Tezcanli E, Yilmaz M, Cizmeli O, Sengoz M, Peker S (2017) Gamma knife radiosurgery for arteriovenous malformations: clinical series of 199 Patients. Turk Neurosurg 27(2):301-308

3. Baujat B, Mahé C, Pignon JP, Hill C (2002) A graphical method for exploring heterogeneity in meta-analyses: application to a meta-analysis of 65 trials. Stat Med 21(18):2641-2652. https:// doi.org/10.1002/sim.1221

4. Bir SC, Ambekar S, Maiti TK, Nanda A (2015) Clinical outcome and complications of gamma knife radiosurgery for intracranial arteriovenous malformations. J Clin Neurosci 22(7):1117-1122

5. Bose R, Agrawal D, Singh M et al (2015) Draining vein shielding in intracranial arteriovenous malformations during gamma-knife: a new way of preventing post gamma-knife edema and hemorrhage. Neurosurgery 76(5):623-632. https://doi.org/10.1227/ NEU.0000000000000660

6. Chang JH, Chang JW, Park YG, Chung SS (2000) Factors related to complete occlusion of arteriovenous malformations after gamma knife radiosurgery. J Neurosurg 93(Suppl 3):96-101. https://doi.org/10.3171/sup.2000.93.supplement3.0096

7. Chen CJ, Ding D, Kano H et al (2018) Stereotactic radiosurgery for pediatric versus adult brain arteriovenous malformations. Stroke 49(8): 1939-1945

8. Choe JG, Im YS, Kim JS, Hong SC, Shin HJ, Lee JI (2008) Retrospective analysis on 76 cases of cerebral arteriovenous malformations treated by gamma knife radiosurgery. J Korean Neurosurg Soc 43(6):265-269. https://doi.org/10.3340/jkns.2008.43.6.265

9. Choi JH, Mohr JP (2005) Brain arteriovenous malformations in adults. Lancet Neurol 4(5):299-308. https://doi.org/10.1016/ S1474-4422(05)70073-9

10. Dawkins AA, Evans AL, Wattam J et al (2007) Complications of cerebral angiography: a prospective analysis of 2,924 consecutive procedures. Neuroradiology 49:753-759

11. DerSimonian R, Laird N (1986) Meta-analysis in clinical trials. Control Clin Trials 7(3):177-188. https://doi.org/10.1016/01972456(86)90046-2

12. Ding D, Starke RM, Sheehan JP (2017) Radiosurgery for the management of cerebral arteriovenous malformations. Handb Clin Neurol 143:69-83. https://doi.org/10.1016/B978-0-444-636409.00007-2

13. Ding D, Yen CP, Starke RM, Xu Z, Sheehan JP (2014) Radiosurgery for ruptured intracranial arteriovenous malformations. J Neurosurg 121(2):470-481. https://doi.org/10.3171/2014.2.JNS13 1605

14. Ding D, Yen CP, Starke RM, Xu Z, Sun X, Sheehan JP (2014) Outcomes following single-session radiosurgery for high-grade intracranial arteriovenous malformations. Br J Neurosurg 28(5):666-674
15. Ding D, Yen CP, Starke RM, Xu Z, Sun X, Sheehan JP (2014) Radiosurgery for Spetzler-Martin Grade III arteriovenous malformations. J Neurosurg 120(4):959-969

16. Ding D, Yen CP, Xu Z, Starke RM, Sheehan JP (2014) Radiosurgery for low-grade intracranial arteriovenous malformations. J Neurosurg 121(2):457-467

17. Ding D, Yen CP, Xu Z, Starke RM, Sheehan JP (2013) Radiosurgery for patients with unruptured intracranial arteriovenous malformations. J Neurosurg 118(5):958-966. https://doi.org/10. 3171/2013.2.JNS121239

18. Ditty BJ, Omar NB, Foreman PM et al (2017) Seizure outcomes after stereotactic radiosurgery for the treatment of cerebral arteriovenous malformations. J Neurosurg 126(3):845-851

19. Flickinger JC, Kondziolka D, Lunsford LD et al (2000) Development of a model to predict permanent symptomatic postradiosurgery injury for arteriovenous malformation patients. Arteriovenous Malformation Radiosurgery Study Group. Int J Radiat Oncol Biol Phys 46(5):1143-1148. https://doi.org/10.1016/s03603016(99)00513-1

20. Flickinger JC, Kondziolka D, Maitz AH, Lunsford LD (2002) An analysis of the dose-response for arteriovenous malformation radiosurgery and other factors affecting obliteration. Radiother Oncol 63(3):347-354. https://doi.org/10.1016/s0167-8140(02) 00103-2

21. Flickinger JC, Kondziolka D, Maitz AH, Lunsford LD (1998) Analysis of neurological sequelae from radiosurgery of arteriovenous malformations: how location affects outcome. Int J Radiat Oncol Biol Phys 40(2):273-278. https://doi.org/10.1016/s03603016(97)00718-9

22. Flickinger JC, Lunsford LD, Kondziolka D et al (1992) Radiosurgery and brain tolerance: an analysis of neurodiagnostic imaging changes after gamma knife radiosurgery for arteriovenous malformations. Int J Radiat Oncol Biol Phys 23(1):19-26. https://doi. org/10.1016/0360-3016(92)90539-t

23. Fokas E, Henzel M, Wittig A, Grund S, Engenhart-Cabillic R (2013) Stereotactic radiosurgery of cerebral arteriovenous malformations: long-term follow-up in 164 patients of a single institution. J Neurol 260(8):2156-2162. https://doi.org/10.1007/ s00415-013-6936-9

24. Franzin A, Snider S, Boari N et al (2013) Evaluation of prognostic factors as predictor of AVMS obliteration after Gamma Knife radiosurgery. Acta Neurochir (Wien) 155(4):619-626

25. Freeman MF, Tukey JW (1950) Transformations related to the angular and the square root. Ann Math Stat 21(4):607-611, 605

26. Friedlander RM (2007) Clinical practice. Arteriovenous malformations of the brain. N Engl J Med. 356(26):2704-2712. https:// doi.org/10.1056/NEJMcp067192

27. Friedman WA, Blatt DL, Bova FJ, Buatti JM, Mendenhall WM, Kubilis PS (1996) The risk of hemorrhage after radiosurgery for arteriovenous malformations. J Neurosurg 84(6):912-919. https:// doi.org/10.3171/jns.1996.84.6.0912

28. Fukuda K, Majumdar M, Masoud H et al (2017) Multicenter assessment of morbidity associated with cerebral arteriovenous malformation hemorrhages. J Neurointerv Surg 9(7):664-668. https://doi.org/10.1136/neurintsurg-2016-012485

29. Ganz J (1997) Gamma Knife. Surgery. https://doi.org/10.1007/ 978-3-7091-6831-8

30. Graffeo CS, Sahgal A, De Salles A et al (2020) Stereotactic radiosurgery for Spetzler-Martin grade I and II arteriovenous malformations: International Society of Stereotactic Radiosurgery (ISRS) Practice Guideline. Neurosurgery 87(3):442-452. https:// doi.org/10.1093/neuros/nyaa004

31. Han JH, Kim DG, Chung HT et al (2008) Clinical and neuroimaging outcome of cerebral arteriovenous malformations after Gamma Knife surgery: analysis of the radiation injury rate depending on the arteriovenous malformation volume. $\mathbf{J}$ 
Neurosurg 109(2):191-198. https://doi.org/10.3171/JNS/2008/ $109 / 8 / 0191$

32. Hasegawa H, Hanakita S, Shin M et al (2018) Comparison of the long-term efficacy and safety of gamma knife radiosurgery for arteriovenous malformations in pediatric and adult patients. Neurol Med Chir (Tokyo) 58(6):231-239

33. Heiserman JE, Dean BL, Hodak JA et al (1994) Neurologic complications of cerebral angiography. AJNR Am J Neuroradiol 15:1401-1411

34. Higgins JP, Thompson SG, Deeks JJ, Altman DG (2003) Measuring inconsistency in meta-analyses. BMJ 327(7414):557-560. https://doi.org/10.1136/bmj.327.7414.557

35. Hirschmann D, Goebl P, Witte FH et al (2020) Evaluation of the radiosurgical treatment of cerebral arteriovenous malformations: a retrospective single-center analysis of three decades. J Neurointerv Surg 12(4):401-406

36. Hu YS, Lee CC, Wu HM et al (2020) Stagnant venous outflow predicts brain arteriovenous malformation obliteration after gamma knife radiosurgery without prior intervention. Neurosurgery 87(2):338-347

37. Ilyas A, Chen CJ, Ding D et al (2018) Cyst formation after stereotactic radiosurgery for brain arteriovenous malformations: a systematic review. J Neurosurg 128(5):1354-1363. https://doi.org/ 10.3171/2016.12.JNS162478

38. Ilyas A, Chen CJ, Ding D et al (2018) Radiation-induced changes after stereotactic radiosurgery for brain arteriovenous malformations: a systematic review and meta-analysis. Neurosurgery 83(3):365-376. https://doi.org/10.1093/neuros/nyx502

39. Izawa M, Hayashi M, Chernov M et al (2005) Long-term complications after gamma knife surgery for arteriovenous malformations. J Neurosurg 102(Suppl):34-37. https://doi.org/10.3171/jns. 2005.102.s_supplement.0034

40. Kano H, Flickinger JC, Tonetti D et al (2017) Estimating the Risks of Adverse Radiation Effects After Gamma Knife Radiosurgery for Arteriovenous Malformations. Stroke 48(1):84-90. https://doi. org/10.1161/STROKEAHA.116.014825

41. Kano H, Flickinger JC, Yang HC et al (2014) Stereotactic radiosurgery for Spetzler-Martin Grade III arteriovenous malformations. J Neurosurg 120(4):973-981. https://doi.org/10.3171/2013. 12.JNS131600

42. Kano H, Kondziolka D, Flickinger JC et al (2012) Aneurysms increase the risk of rebleeding after stereotactic radiosurgery for hemorrhagic arteriovenous malformations. Stroke 43(10):25862591. https://doi.org/10.1161/STROKEAHA.112.664045

43. Kano H, Kondziolka D, Flickinger JC et al (2012) Stereotactic radiosurgery for arteriovenous malformations, Part 4: management of basal ganglia and thalamus arteriovenous malformations. J Neurosurg 116(1):33-43

44. Kano H, Kondziolka D, Flickinger JC et al (2012) Stereotactic radiosurgery for arteriovenous malformations, Part 5: management of brainstem arteriovenous malformations. J Neurosurg 116(1):44-53. https://doi.org/10.3171/2011.9.JNS11176

45. Kano H, Lunsford LD, Flickinger JC et al (2012) Stereotactic radiosurgery for arteriovenous malformations, Part 1: management of Spetzler-Martin Grade I and II arteriovenous malformations. J Neurosurg 116(1):11-20. https://doi.org/10.3171/2011.9. JNS101740

46. Kim BS, Yeon JY, Kim JS, Hong SC, Shin HJ, Lee JI (2019) Gamma knife radiosurgery for ARUBA-eligible patients with unruptured brain arteriovenous malformations. J Korean Med Sci. 34(36):e232

47. Kiran NA, Kale SS, Kasliwal MK et al (2009) Gamma knife radiosurgery for arteriovenous malformations of basal ganglia, thalamus and brainstem-a retrospective study comparing the results with that for AVMs at other intracranial locations. Acta Neurochir (Wien) 151(12):1575-1582
48. Lee CC, Reardon MA, Ball BZ et al (2015) The predictive value of magnetic resonance imaging in evaluating intracranial arteriovenous malformation obliteration after stereotactic radiosurgery. J Neurosurg 123(1):136-144. https://doi.org/10.3171/2014.10. JNS141565

49. Liscák R, Vladyka V, Simonová G et al (2007) Arteriovenous malformations after Leksell gamma knife radiosurgery: rate of obliteration and complications. Neurosurgery 60(6):1005-1016. https://doi.org/10.1227/01.NEU.0000255474.60505.4A

50. Maruyama K, Kawahara N, Shin M et al (2005) The risk of hemorrhage after radiosurgery for cerebral arteriovenous malformations. N Engl J Med 352(2):146-153. https://doi.org/10.1056/ NEJMoa040907

51. Matsunaga S, Shuto T (2014) Long-term outcomes of gamma knife surgery for posterior fossa arteriovenous malformations. Neurol Med Chir (Tokyo) 54(10):799-805

52. Missios S, Bekelis K, Al-Shyal G, Rasmussen PA, Barnett GH (2014) Stereotactic radiosurgery of intracranial arteriovenous malformations and the use of the $\mathrm{K}$ index in determining treatment dose. Neurosurg Focus 37(3):E15

53. Moher D, Liberati A, Tetzlaff J, Altman DG, PRISMA Group (2009) Preferred reporting items for systematic reviews and metaanalyses: the PRISMA statement. PLoS Med. 6(7):e1000097. https://doi.org/10.1371/journal.pmed.1000097

54. Nicolato A, Foroni R, Crocco A et al (2002) Gamma knife radiosurgery in the management of arteriovenous malformations of the Basal Ganglia region of the brain. Minim Invasive Neurosurg 45(4):211-223. https://doi.org/10.1055/s-2002-36200

55. Niranjan A, Kano H, Lunsford L (2012) Gamma knife radiosurgery for brain vascular malformations. Prog Neurol Surg. https:// doi.org/10.1159/isbn.978-3-8055-9620-6

56. Orio P, Stelzer KJ, Goodkin R, Douglas JG (2006) Treatment of arteriovenous malformations with linear accelerator-based radiosurgery compared with Gamma Knife surgery. J Neurosurg 105(Suppl):58-63. https://doi.org/10.3171/sup.2006.105.7.58

57. Pan DH, Guo WY, Chung WY, Shiau CY, Chang YC, Wang LW (2000) Gamma knife radiosurgery as a single treatment modality for large cerebral arteriovenous malformations. J Neurosurg 93(Suppl 3):113-119. https://doi.org/10.3171/jns.2000.93.suppl ement

58. Parkhutik V, Lago A, Aparici F et al (2013) Late clinical and radiological complications of stereotactical radiosurgery of arteriovenous malformations of the brain. Neuroradiology 55(4):405-412

59. Pollock BE, Flickinger JC, Lunsford LD, Bissonette DJ, Kondziolka D (1996) Hemorrhage risk after stereotactic radiosurgery of cerebral arteriovenous malformations. Neurosurgery 38(4):652-661

60. Pollock BE, Flickinger JC, Lunsford LD, Maitz A, Kondziolka D (1998) Factors associated with successful arteriovenous malformation radiosurgery. Neurosurgery 42(6):1239-1247. https://doi. org/10.1097/00006123-199806000-00020

61. Pollock BE, Flickinger JC (2002) A proposed radiosurgery-based grading system for arteriovenous malformations. J Neurosurg 96(1):79-85. https://doi.org/10.3171/jns.2002.96.1.0079

62. Pollock BE, Flickinger JC (2008) Modification of the radiosurgery-based arteriovenous malformation grading system. Neurosurgery 63(2):239-243. https://doi.org/10.1227/01.NEU.00003 15861.24920 .92

63. Pollock BE, Kondziolka D, Flickinger JC, Patel AK, Bissonette DJ, Lunsford LD (1996) Magnetic resonance imaging: an accurate method to evaluate arteriovenous malformations after stereotactic radiosurgery. J Neurosurg 85(6):1044-1049. https://doi.org/10. 3171/jns.1996.85.6.1044

64. Pollock BE, Link MJ, Stafford SL, Garces YI, Foote RL (2016) Stereotactic radiosurgery for arteriovenous malformations: the 
effect of treatment period on patient outcomes. Neurosurgery 78(4):499-509

65. Raboud M, Tuleasca C, Maeder P et al (2018) Gamma knife radiosurgery for arteriovenous malformations: general principles and preliminary results in a Swiss cohort. Swiss Med Wkly 148:w14602

66. Solomon RA, Connolly ES Jr (2017) Arteriovenous Malformations of the Brain. N Engl J Med 376(19):1859-1866. https://doi. org/10.1056/NEJMra1607407

67. Spetzler RF, Martin NA (1986) A proposed grading system for arteriovenous malformations. J Neurosurg 65(4):476-483. https:// doi.org/10.3171/jns.1986.65.4.0476

68. Stapf C, Mast H, Sciacca RR et al (2003) The New York Islands AVM Study: design, study progress, and initial results. Stroke 34(5):e29-e33. https://doi.org/10.1161/01.STR.0000068784. 36838.19

69. Starke RM, Kano H, Ding D et al (2017) Stereotactic radiosurgery for cerebral arteriovenous malformations: evaluation of longterm outcomes in a multicenter cohort. J Neurosurg 126(1):36-44. https://doi.org/10.3171/2015.9.JNS151311

70. Sterne JA, Hernán MA, Reeves BC et al (2016) ROBINS-I: a tool for assessing risk of bias in non-randomised studies of interventions. BMJ 355:i4919. https://doi.org/10.1136/bmj.i4919 (Published 2016 Oct 12)

71. Tuleasca C, Peciu-Florianu I, Leroy HA, Vermandel M, Faouzi M, Reyns N (2020) Biologically effective dose and prediction of obliteration of unruptured arteriovenous malformations treated by upfront Gamma Knife radiosurgery: a series of 149 consecutive cases. J Neurosurg. 134(6):1901-1911. https://doi.org/10.3171/ 2020.4.JNS201250 (Published 2020 Jul 24)

72. van Beijnum J, van der Worp HB, Buis DR et al (2011) Treatment of brain arteriovenous malformations: a systematic review and meta-analysis. JAMA 306(18):2011-2019. https://doi.org/10. 1001/jama.2011.1632

73. Yen CP, Sheehan JP, Schwyzer L, Schlesinger D (2011) Hemorrhage risk of cerebral arteriovenous malformations before and during the latency period after GAMMA knife radiosurgery. Stroke 42(6): 1691-1696. https://doi.org/10.1161/STROKEAHA. 110.602706

74. Zeiler FA, McDonald PJ, Kaufmann A et al (2011) Gamma knife for cerebral arteriovenous malformations at a single centre. Can J Neurol Sci 38(6):851-857

75. Zhao G, Liang JC, Wang WM et al (2008) Long-term effects of gamma-knife radiosurgery for cerebral arteriovenous malformation. Neurosurg Q 18:126-129

Publisher's note Springer Nature remains neutral with regard to jurisdictional claims in published maps and institutional affiliations. 